\title{
Maintenance of heritage architecture: implementation and practice
}

\author{
D. Lazarus \\ Arup Advanced Technology and Research Group, UK
}

\begin{abstract}
While maintenance has been defined in slightly different terms by various bodies and standards, the underlying philosophy was eloquently expressed in the 19C by William Morris as "to stave off decay by daily care" and adopted in the manifesto of the Society for the Protection of Ancient Buildings. Maintain our Heritage was formed in 1999 specifically to promote a new, long-term, sustainable strategy for the care of historic buildings with pre-eminence given to maintenance rather than sporadic major repair. Attitudes differ internationally as to the imperative for such work and the extent to which it should be publicly regulated and funded. Owners may recognise the benefits but lack either the resource or indeed the knowledge as to what should be done. While all European countries have a statutory system for the identification and protection of buildings and structures considered to be of cultural significance, the degree of support from the different states shows significant variation. Monumentenwacht (literally 'Monument watch') started in the Netherlands in 1973 on a very small scale: it now has a substantial provincial subsidy for its operation and has also been established elsewhere in Continental Europe. Within the UK, although there are national heritage organisations, the position in terms of financial support is very different. There is a need for collaborative research into appropriate methods and materials for such work, and for widespread dissemination of the findings, in order to avoid a repetition of damage to historic fabric acknowledged to have been caused in the past. This paper explores the separate themes identified above, including recommendations for the management and implementation of systematic maintenance.
\end{abstract}

Keywords: inspection, systematic maintenance, prevention, plans, duty of care, management, access, log book. 


\section{Introduction}

At the outset it is necessary both to understand both the meaning of maintenance in the context used here and the enormous range of buildings and building fabric considered. Maintenance is defined in BS 7913 [1] as "Routine work necessary to keep the fabric of a building, the moving parts of machinery, grounds gardens or any other artefact, in good order." It is taken to encompass routine and systematic operations, which may include minor repairs but not work of a more major character. 'Heritage architecture' in turn covers a wide spectrum, from private residences built in the vernacular style, or even smaller structures, to large and elaborate public buildings, and also monumental architecture.

Other definitions of Maintenance can be found, for example in the Burra Charter [2], which gives us: "Maintenance means the continuous protective care of the fabric and setting of a place, and is to be distinguished from repair. Repair involves restoration or reconstruction."

The Charter then elaborates further on this definition in order to define some of the commonly used terms, "The distinctions referred to, for example in relation to roof gutters, are:

- maintenance - regular inspection and cleaning of gutters;

- repair involving restoration - returning of dislodged gutters;

- repair involving reconstruction - replacing decayed gutters"

English Heritage in its guidance on maintenance plans [3] explains that maintenance itself falls into three main categories:

- Inspection and assessment of what is required

- $\quad$ Specific tasks

- Implementation of necessary minor repairs

Again, it is emphasised that more significant repairs are not included within the scope of maintenance, the intention being that regular, planned maintenance should be undertaken as the most effective means of avoiding, or at least minimising, such work.

While there may be factors leading to delay in minor repairs as part of routine maintenance e.g. short-term funding issues, disruption, natural inertia, the more significant work required at a later date if no preventative action is taken may well lead to the loss of historic fabric. For example, failure to remove vegetation from walls or gutters can lead to damage to joints or water seepage, either of which may result in water ingress to the interior and the potential for major damage to fabric.

A research programme, Maintaining Value, was commissioned by Maintain our Heritage $(\mathrm{MoH})$ in 2002 to report on current practice with regards to systematic maintenance, principally of historic buildings but also of the building stock more generally. This paper draws in part on the outputs from the programme and the summary report issued by $\mathrm{MoH}$ at its conclusion [4]. 


\section{The case for maintenance of heritage architecture}

The importance of maintenance to the ongoing life of a building (or equally a monument, landscape etc) is recognised by all bodies concerned with the protection and care of fabric, and in this case the specific care of historic fabric.

This is enshrined within, for example, the Burra Charter, at Article 16: "Maintenance is fundamental to conservation and should be undertaken where fabric is of cultural significance and its maintenance is necessary to retain that cultural significance."

Power of Place [5] notes additionally that regular conservation and maintenance activities also promote regeneration through the creation of longterm, sustainable employment. The balance between labour and materials for repair and restoration lies firmly in favour of labour, by contrast with new-build.

The Society for the Protection of Ancient Buildings ('SPAB') was founded by William Morris in 1877 to counteract the highly destructive 'restoration' of medieval buildings being practised by many Victorian architects. He pleaded for those entrusted with old buildings 'to stave off decay by daily care', which might be suitably interpreted here as routine, ongoing maintenance. The SPAB website [http://www.spab.org.uk/] provides the following, of particular relevance here:

"The importance of preventative maintenance cannot be over-emphasised. Such action will not only restrain, or even obviate, the need for repairs later; it will prevent the loss of original fabric and is cost-effective. Without such action, owners are often surprised how quickly a structure can deteriorate. Resultant corrective maintenance is disruptive and costly in both fabric and financial terms."

$\mathrm{MoH}$ [4] point out that "Maintenance is central to protecting cultural significance because, if properly implemented, it is the least destructive of all the 'interventions', which inevitably occur in the process of conserving historic buildings." The fabric of the building is important in itself - not just the function it performs. This is recognised in all the key national and international documents on the protection of historic buildings.

Again, in England, this is reinforced in Planning Policy Guidance Note 15[6] where the importance of regular maintenance and repair to the preservation of historic buildings is emphasised. It is noted that a modest outlay on such activities will keep a building weathertight, and in particular repairs to roofs, with regular clearance of gutters and downpipes can prevent much more expensive work becoming necessary subsequently.

There are numerous examples of both the consequences of failure to maintain and cases where good practice has been implemented.

\section{Implementation of routine maintenance practice}

\subsection{Statutory duty of care}

While all European Nations have a statutory system for the identification and protection of buildings and structures considered to be of cultural significance, 
the positive contribution from the state towards the 'protection' aspects is much more significant in Continental Europe than in the United Kingdom. This is discussed further below.

In other countries there may be an obligation to maintain, although it is interesting to note that, for example, the Vancouver Municipal Code [9] actually excludes 'historic buildings' from the relevant provisions for "minimum maintenance standards for buildings, yards, facilities and equipment", provided there is no general compromise of public interests in relation to health, safety and welfare.

The heritage protection system in Australia, which is operated through individual state legislation, has some resonance with that in the UK, although there are stricter obligations on owners. In Victoria, for example, if a property is recognised as being of State significance and is therefore on the Victorian Heritage Register, the owner is obligated to maintain the property such that it neither falls into disrepair nor sustains a threat to its conservation.

If the owner fails to act accordingly there are set procedures that are followed, with the Executive Director holding the ultimate right to carry out the works himself and recover costs.

Within the UK, the regulatory requirement for buildings (in certain uses) to be appropriately strong and stable [7] does not impose a more general requirement to maintain within the context considered here. For many heritage buildings in the UK, maintenance is likely to be at best responsive and in many cases nugatory. For most listed buildings there is no duty of care, with the obligation to maintain and repair being no different to that for any other building. It is anomalous that listed building consent is required for many categories of work that might be contemplated, but there is no actual obligation to keep the building in repair more generally.

Part of the research for MoH looked at the differences between 'heritage' and 'non-heritage' organisations in the care of their listed building stock. While it was found that the heritage organisations showed a greater awareness of the relationship between maintenance and cultural significance, it appeared that neither group presented what might be considered to be a best practice approach to maintenance.

It should also be remembered that there is a significant amount of listed building stock, often residential, in the hands of private owners, and this creates a very distinct and separate constituency in relation to care and maintenance.

There are examples from Europe of initiatives, which either take, or help to support, a systematic approach to the maintenance of listed/historic buildings. Looking at these allows a vision of how protection on a much wider scale internationally might be encouraged, utilising the key features from these schemes.

\subsection{National maintenance practice - some examples}

\subsubsection{Monumentenwacht in Northern Europe}

The establishment of Monumentenwacht organisations in a number of countries, based on the original model from the Netherlands, provides both a framework for 
the care of historic buildings and a positive statement as to the importance accorded to such buildings by the state.

Monumentenwacht began in the Netherlands in 1973 with one part-time team of inspectors. By 2002 the number had increased to 52 teams working on a fulltime basis, looking after over 15000 monuments. There is now a substantial provincial subsidy for the inspectors' salaries and labour costs. The building owners pay a membership fee and an inspection fee.

The principal role of the inspectors in these organisations is to give recommendations for maintenance and repair that is needed, based on their inspection, but they also carry out minor and urgent repairs

The operation of the system is demonstrating the benefits of regular maintenance to both the government and the owners. Monumentenwacht in Flanders ['Monumentenwacht Vlaanderen vzw'] operates a state-subsidised inspection system for heritage buildings. [http://www.monument.vlaanderen.be]. This is very similar to the original Monumentenwacht Nederland. Other systems have also been established in Continental Europe, including in Denmark in 2000 (see below), and in the Berlin and Brandenburg area of Germany [9].

\subsubsection{Denmark-Raadvad Bygingssyn}

This service, also inspired by Monumentenwacht, was established in 2000 as Raadvad's Building Care. This initiative provides an annual inspection as part of a subscription service, principally of the exterior but also looking at basements and attics, by craftsmen with the necessary training. There is also a one-off inspection offered within the maintenance and repair consultancy service.

The report from the inspection will identify the general condition of the building, together with a prioritised schedule of items requiring repair or other attention. It also provides a schedule of maintenance activities that should be undertaken at various intervals. Minor items requiring urgent attention will be repaired at least on a temporary basis as part of the inspection service. Gutters and downpipes will also be cleaned as a routine procedure.

The provision of this service is beneficial particularly to private owners of listed buildings who, like their public counterparts, are obliged to maintain their properties, although even with this obligation subsidies are generally focused on repairs rather than maintenance.

\subsubsection{Italy - the risk map of cultural heritage}

The Risk Map is not an offshoot of the Monumentenwacht concept, but provides a comprehensive national catalogue of state-owned protected structures, which in this context includes buildings, conservation areas and landscapes. This is a database of information on the condition of these structures and the environment in which they are located, and is available to both central and local administration with responsibility for cultural heritage.

The database contains a 'vulnerability index' for these protected structures, with three different 'danger factors' (static-structural danger, environmental air danger, human danger) and their distribution across the country.

The data has been adopted and used to develop regional initiatives. For example, the risk map has been used in Lombardia to develop its approach to 
planned conservation. This is in contrast to the more traditional approach of reactive intervention after damage has occurred, and attempts to promote planned preventative maintenance for protected structures.

\subsubsection{United Kingdom}

Within the UK there has been no similar national scheme, but a pilot scheme was set up and operated in Bath by $\mathrm{MoH}$ to explore the potential for a Monumentenwacht-type of approach here.

The 'Bath Area Pilot', undertaken in 2002-3, was the first maintenance inspection scheme for historic buildings in the country. It demonstrated that such a scheme could be operated both technically and legally, but as yet there has been no widespread take-up of such a scheme elsewhere. The Pilot was grantaided, and it is clear from feedback that significant public subsidy would be required to establish and operate a scheme on a more permanent basis.

In Edinburgh there has been a history of potentially - and in one case actually - fatal falls of stone from buildings. This is part of a more systematic maintenance problem also seen in England (and reported from the USA), which has prompted a citywide audit, by the council to investigate maintenance records and consider the establishment of a database. It is planned to make a survey every five years compulsory for these 'hotspot' properties in a move to identify such problems before they become serious.

SPAB promotes National Maintenance Week annually, an awareness campaign largely designed to encourage anyone who cares for a property, to be aware of the simple, practical maintenance steps to take at the beginning of winter to prepare for the worst that the weather can bring.

\subsection{Access: health and safety issues}

It is clear that access is a problem with regard to the implementation of routine maintenance as well as for other work. This is seen for a wide variety of buildings: even for those domestic buildings which might be considered to be 'small', the means of safe access for roof inspections or gutter cleaning can be costly and difficult to organise.

For older buildings, erected long before health and safety issues were a major consideration, access even to internal areas can be less than ideal and access to roof spaces and onto the roofs themselves can pose severe challenges.

The programming of repairs for places of worship with their high roofs presents particular difficulties. It has been noted [10] that the worst problems are often found in the places that are hardest - and perhaps most dangerous - to access, but that appropriate access arrangements need to be made. There is also a widespread incidence on some of the best buildings in this category of very poor drainage arrangements from both roofs and walls. 


\subsection{The need for appropriate specialists}

Implementation of inspection and maintenance, and of more significant work where indicated, may be constrained not just by issues of access, money and disruption, all or any of which may be important for a given building, but also by shortage of appropriately skilled specialists to undertake the work. The need for skilled craftsmen and inspectors is widely recognised and has to be addressed as a matter of urgency if there is to be a serious expansion of maintenance initiatives.

It is recognised that inappropriate work has been carried out that has subsequently led to damage to the possibly fragile fabric that was being repaired. While in some cases this was due to lack of knowledge at the time, in others it is due to the employment of inadequately trained specialists.

In Denmark, formal consideration of the maintenance and restoration of architectural heritage goes back to 1977 when the Council of Europe funded a craft-training centre in Venice. This was followed by the establishment of similar centres in Germany, France and Austria, with Raadvad, the Nordic Centre for Traditional Crafts opened in 1987 a short distance from Copenhagen.

$\mathrm{MoH}$ concluded that "There is a shortage of properly trained and qualified builders able to undertake maintenance on historic properties". There are also concerns that there is a similar shortfall in those trained to undertake the inspections that constitute the first part of the process.

Again, it is probably the private owners who have the greatest need for clear information as to reputable and suitably experience consultants and specialist craftsman.

\subsection{Considerations for the future}

There are several aspects of concern for heritage architecture in relation to climate change, of which perhaps two are of relevance here. There may be a conflict between statutory and/or economic requirements for reducing energy consumption and the impact this may have on historic fabric as the past, stable environment is changed. Thus intervention many be required that might not otherwise have been foreseen, due to disturbance of the equilibrium position.

The second aspect relates to the direct consequences of the changing climate. Of these, it is likely that changes in moisture levels will be of greatest significance. English Heritage commissioned a scoping study in 2002 on climate change and the historic environment [11]. One of the key recommendations was that the organization needed to address the way in which it currently carries out monitoring, management and maintenance so that it would have the ability to "improve the stability of the historic environment" whatever the impact of climate change.

This is a recognised area where further research is needed and where there will be important opportunities to share knowledge within the heritage community. 


\section{Recommendations for systematic maintenance}

\subsection{Maintain our heritage}

MoH's own summary report on their research programme contains a number of conclusions and recommendations. Amongst these, the following are highlighted:

- The role of innovative technologies in parallel with more traditional methods for maintenance work is emphasised.

- It is recommended that a central repository of information on the care and maintenance of heritage buildings, ideally web-based, should be created, particularly for ht benefit of private, domestic owners.

- Further consideration is needed in relation to safe access methods for heritage buildings.

The importance of inspection as part of the preventative maintenance regime has to be recognised. All activities need to be planned and follow-up actions identified and acted upon.

\subsection{Routine inspections}

All organisations emphasise the importance of routine inspections. BS 7913 explicitly recommends that the condition of any building should be reviewed every five years - the same interval which has statutory recognition for English parish churches.

\subsection{The owner's log book}

For heritage buildings it is suggested that a Log Book should be created, and passed on to subsequent owners. This would include information on, for example, the history of the property, including construction materials and special features, any existing maintenance regime and contact details for specialists and maintenance contractors.

The use of such a document, which is also a recommendation of BS 7913, could undoubtedly assist in conserving properties in good condition, and engaging the owners in the cultural importance of their assets.

\section{Recent technical advances in maintenance practice}

\subsection{Materials}

A material often associated with heritage buildings is 'lime' - as mortar, render, plaster or limewash. The benefits of lime are being more widely disseminated, not only within the context of conservation and maintenance work but also for new construction. Research continues into its use, in part to ensure compatibility of new repair mortars with the original materials. 
Other materials which may need to be suitably sourced and integrated with existing include stone, brick, timber, paints and coatings. The potential for the use of new materials for such applications should also be recognised and kept under review.

\subsection{Techniques}

Both conventional and innovative conservation techniques should be considered. The latter may provide more cost effective means of protecting buildings than those that are more familiar, and they may be able to solve problems that in previous centuries did not have a sympathetic solution. However, where they are not yet fully proven it is unlikely that they will be immediately adopted for historic buildings, but worth developing further with that intention in mind. Both materials and new techniques need a full understanding if they are not to be applied inappropriately by the uninformed user.

As noted earlier, while access provision has been improved, there are much greater constraints in terms of health and safety requirements. A significant advance, therefore, has been the development of remote monitoring devices which remove the need for routine access to areas where this is difficult and/or expensive and mean that this is needed only where there is a clear indication of the need for manual intervention.

Such systems can be used to monitor a number of parameters, including the moisture content of timber in vulnerable areas, gutter overflows and leaking downpipes. The technology has been used at a number of significant historic buildings, and enables remote monitoring to be undertaken, both locally and even for buildings in another country.

It is important to recognise that while inspection and monitoring may identify particular problems or defects they will not necessarily identify the cause. Such identification is essential in order to determine the appropriate remedy.

\section{Acknowledgements}

Maintain our Heritage, http://www.maintainourheritage.co.uk/; University of the West of England, Bristol (Research Modules 1-3 for $\mathrm{MoH}$ programme 'Maintaining Value')

\section{References}

[1] BS 7913: 1998 Guide to the principles of the conservation of historic Buildings, British Standards Institution, London

[2] Australia ICOMOS Burra Charter, 1999

[3] Grants for Historic Buildings, Monuments and Designed Landscapes, English Heritage 2004.

[4] Putting it off: how lack of maintenance fails our heritage. Maintain our Heritage, 2004 
328 Structural Studies, Repairs and Maintenance of Heritage Architecture X

[5] Power of Place - the Future of the Historic Environment. English Heritage 2000

[6] Planning Policy Guidance Note 15: Planning and the historic environment. Department of the Environment /Department of National Heritage, 1994

[7] Vancouver Municipal Code Section 17.14.020 Scope

[8] Amendment to the Workplace (Health, Safety and Welfare) Regulations 1992 as amended 2002. Her Majesty's Stationery Office, London.

[9] Arup Research and Development, Maintaining Value Research Module 4. 2003

[10] Martin Ashley, Programming Repairs The Conservation and Repair of Ecclesiastical Buildings, 1998

[11] Climate Change and the Historic Environment, Centre for Sustainable Heritage, University College London, 2005 